\title{
ЖУРНАЛИСТИКА
}

\author{
УДК 070.15
}

DOI: $10.17223 / 19986645 / 38 / 12$

\section{Д.А. Кунильский}

\section{ДИАЛОГ «ПОЛОЖИТЕЛЬНОГО» И «ОТРИЦАТЕЛЬНОГО» НАПРАВЛЕНИЙ В РУССКОЙ ЖУРНАЛИСТИКЕ 1860-х гГ. ${ }^{1}$}

\begin{abstract}
В статье отечественная журналистика ХIX в. рассматривается как диалог двух направлений - «положительного» и «отрицательного». Представлена история этих понятий, приведены случаи их использования в критических и публицистических статьях. Наиболее четко разделение на «положительную» $u$ «отрищательную» части прослеживается в журналистике шестидесятых годов и показано на примере разнообразных откликов на роман И.С. Тургенева «Отиы и дети».

Ключевые слова: журналистика, полемика, «положительное» $u$ «отрицательное» направления, «Отияы и дети», нигилизм.
\end{abstract}

В публицистических и литературно-критических статьях, принадлежащих разным авторам XIX в., начиная с 1820-х гг. обращает на себя внимание намеренный повтор слов «положительное» и «отрицательное», причем смысл, который вкладывался в эти понятия, не был одинаковым. Многое, конечно, зависело от того, какую позицию в общественной жизни и журнальной полемике занимал литератор. Цель настоящей статьи состоит в том, чтобы выяснить главные значения терминов «положительное» и «отрицательное», а также определить причину частого использования этой оппозиции именно в критике и публицистике ${ }^{2}$. Ввиду обширности материала основное внимание будет уделено спорам по поводу романа И.С. Тургенева «Отцы и дети», что позволяет локализовать проблему и в то же время показать в диалоге носителей различных идей.

Таким образом, объектом исследования являются статьи М.А. Антоновича, Д.И. Писарева и М.Н. Каткова, в которых обсуждался новый роман, а предметом - значение встречающегося в этих статьях термина «отрицательное направление», а также противоположного по отношению к нему понятия «положительное». Крайне важно рассмотреть историю слов «положительное» и «отрицательное», чтобы представлять, о чем дискутировали разные поколения мыслителей и публицистов.

Изучение мировоззренческого и философского контекста бытования названных понятий - отдельная большая тема; здесь имеет смысл охарактери-

\footnotetext{
${ }^{1}$ Статья подготовлена в рамках проекта «Современные аспекты изучения истории и поэтики русской литературы» Программы стратегического развития на 2012-2016 годы «Университетский комплекс ПетрГУ в научно-образовательном пространстве Европейского Севера: стратегия инновационного развития».

${ }^{2}$ Из работ, исследующих использование этих терминов в русской критике и публицистике, могу назвать только диссертацию Т.А. Трофимовой [1].
} 
зовать основные идеи в общих чертах, иначе это уведет нас совсем в другую область. Термины «отрицательное» («отрицание») и «положительное» активно использовались в немецкой философии, в частности Шеллингом, который выделял два типа философского познания - «отрицательное» (логическое, рациональное) и «положительное» (религиозное). Эти взгляды Шеллинга нашли сторонников и в числе русских литераторов. Так, например, будущий славянофил И.В. Киреевский, слушавший в 1830 г. в Мюнхенском университете лекции Шеллинга, в своей известной статье «Девятнадцатый век» (1832) использовал ту же лексику, соглашаясь с немецким философом в его предпочтении «положительной» философии [2. С. 68-69 $]^{1}$. Необходимо отметить, что понятия «положительное» и «отрицательное» также связываются с диалектикой Гегеля и, по мнению некоторых исследователей, являются именно гегелевскими ${ }^{2}$. Другим смыслом один из элементов оппозиции наполняется в трудах основоположника позитивизма О. Конта, там под «положительностью» имеется в виду выдвижение на первый план естественных наук (физики, химии, астрономии, физиологии), ориентация на практическое знание, опора на факты ${ }^{3}$.

В России слова «положительное» и «отрицательное» появляются, очевидно, в первой половине XIX в., в эпоху преобразования русского языка, связанную с именем Н.М. Карамзина ${ }^{4}$, и в большинстве случаев также имеют явную философскую окраску. Надо сказать, что идея «положительного» и «отрицательного» направлений на первых порах развивалась в сфере литературной критики и подразумевала разговор о художественной литературе 5 , a не о журналистике или текущей политической и общественной ситуации. Другое дело, кто вел этот разговор - литературные критики, игравшие ведущую роль в «толстых» журналах. Суть вопроса заключалась в том, как надо изображать современную русскую жизнь: обличая ее недостатки с целью их искоренения или все же показывая светлые стороны как главные ориентиры для дальнейшего развития. Обратимся к свидетельству современника. Ближе к концу столетия сподвижник Ф.М. Достоевского, публицист Д.В. Аверкиев, вспоминая период сороковых годов, писал: «Как известно, в русской словесности различалось два направления: положительное и отрицательное. В отрицательном полагалась вся ее сила и значение. <..> Все “отрицательное”

${ }^{1}$ См.: [3].

2 «Отрицание, - писал Гегель, - непосредственно противостоит реальности... оно противопоставляется положительному, которое есть рефлектирующая в отрицание реальность, - реальность, в которой светится то отрицательное, которое еще скрыто в реальности, как таковой» [4. С. 175]. См.: [5. C. 206].

${ }^{3}$ CM.: [6].

${ }^{4}$ В «Словаре Академии Российской» статей, посвященных этим словам, еще нет [7]. Интересующие нас понятия появляются позднее - в «Общем церковно-славяно-российском словаре» П.И. Соколова [8] и «Словаре церковно-славянского и русского языка» [9] , подготовленном Академией наук в 1847 г. В этих двух словарях «отрицательный» трактуется как «содержащий в себе отрицание, отвержение, отказ», а «положительный» - как «утвердительный, решительный».

${ }^{5}$ Еще в 1827 г. князь П.А. Вяземский с сожалением писал о том, что русская литература пошла по пути, указанному одами Ломоносова, а не сатирами Кантемира. Со страниц «Московского вестника» ему возражал С.П. Шевырев: «Не поэзии дело истреблять плевелы... она положительно действует на человека», «она растворит душу к приятию всего высокого и благородного - и невольно очистятся нравы» [10. С. 59]. 
удостаивалось сугубой внимательности и хвалы; оно усиленно отыскивалось всюду» [11. С. 188].

В этих словах Д.В. Аверкиева угадывается намек на В.Г. Белинского: именно в 1840-е гг. отношение известного критика к русской жизни заметно радикализировалось, соответственно поменялись и его представления о задачах современного искусства. В обновленном «Современнике» В.Г. Белинский пропагандировал «отрицательное направление» новой литературной школы, иронично названной Ф.В. Булгариным «натуральной» (Н.А. Некрасов, И.И. Панаев, И.С. Тургенев, Д.В. Григорович, Е.П. Гребенка и др.). Оппоненты, среди которых были и славянофилы, критиковали натуральную школу за слишком мрачное изображение жизни, чрезмерное преувеличение ее пороков, высокомерное отношение к простым людям ${ }^{1}$. В ответ на обвинения В.Г. Белинский, считавшийся идейным вдохновителем натуральной школы, утверждал, что «привычка верно изображать отрицательные явления жизни даст возможность... когда придет время, верно изображать и положительные явления жизни, не становя их на ходули, не преувеличивая, словом, не идеализируя их реторически» [13. С. 191].

Итак, формула «отрицательное направление» в сороковые годы прочно закрепилась за натуральной школой и ее идеологом В.Г. Белинским. Закономерной реакцией на это со стороны славянофилов стало появление в их журнале «Русская беседа» (1856-1860) ряда критических статей, отстаивающих положительное воззрение на жизнь: «Семейная хроника и Воспоминания, С. Аксакова» (1856) Н.П. Гилярова-Платонова, «Детские годы Багрова внука, служащие продолжением Семейной хроники, С. Аксакова» (1858) С.П. Шевырева, «О положительном и отрицательном отношении к жизни в русской литературе» (1859) А.М. Иванцова-Платонова ${ }^{2}$. Все названные работы убеждали писателей отказаться от «голого отрицания», обращать внимание на светлые стороны национального быта, а первые две в качестве образца называли произведения С.Т. Аксакова.

Очень важно, что разные по своим взглядам авторы часто вкладывали в понятия «положительное» и «отрицательное» неодинаковый смысл. Для того чтобы это показать, позволю себе повторить уже сказанное в других моих работах ${ }^{3}$. Западники и литераторы так называемого «демократического» лагеря во главу угла ставили «отрицание», которое рассматривалось ими как отвержение старого, надоевшего мироустройства, что в конечном счете могло завершиться открытой борьбой с властью. Славянофилы и консервативные публицисты, напротив, выделяли слово «положительное», подразумевая под ним следование христианским идеалам, патриотизм, изучение народной культуры в разнообразных ее проявлениях. Однако представители разных идейных течений вовсе не отказывались от понятий, противоположных тем, значимость которых они отстаивали. «Положительное» также было важно для западнически настроенных литераторов, только трактовалось ими в духе позитивизма - как своеобразный рационализм, жизненный практицизм, отказ

\footnotetext{
${ }^{1}$ См.: [12].

${ }^{2}$ Характерно, что в колонтитуле эта статья обозначена иначе - «О положит[ельном] и отрицат[ельном] направл[ениях] в рус[ской] литературе».

${ }^{3}$ См.: $[12,14]$.
} 
от религиозного мировосприятия. А те же славянофилы провозглашали особый, свойственный им вид отрицания современной действительности - отрицание заимствованных у Запада форм государственной и общественной жизни во имя русской народности и самобытности. В настоящей статье, главным образом, рассматривается значение слов «отрицание» и «отрицательное направление», которые вновь стали использоваться в журнальной полемике в начале 1860-х гг. Поводом к спору послужил роман И.С. Тургенева «Отцы и дети» - первое большое произведение, где был представлен образ современного отрицателя.

Цензурные послабления, возможность высказываться о политических событиях активизировали дискуссии на разные темы. Как известно, уже со второй половины 1850-х гг. авторы рассуждали не только о литературе, но, разбирая литературных героев, художественные образы, старались говорить о настоящем и будущем страны. Статьи стали, так сказать, более публицистичны, злободневны. Разделение журналистики на «положительную» и «отрицательную» части оказалось более очевидным, в программных выступлениях заявлялась принадлежность к той или иной партии ${ }^{1}$. По словам Н.Н. Страхова, «состояние умов в это время, в 1861 и 1862 гг., было в высшей степени возбужденное» [17. С. 234], и именно тогда вновь актуализировались слова «отрицательное направление», «отрицание», «нигилизм». Важную роль здесь сыграл роман Тургенева «Отцы и дети» (1862 г.), «в котором в первый раз появилось слово нигилист, с которого начались толки о новых людях и, словом, все дело получило определенность и общеизвестность» [13. С. 236] 2 . Отзывы на новое произведение часто противоречили друг другу - возьмем только самые известные из них: статьи М.А. Антоновича «Асмодей нашего времени» (Современник. 1862. № 3), Д.И. Писарева «Базаров» (Русское слово. 1862. № 3) и написанные уже с учетом этих публикаций две работы М.Н. Каткова - «Роман Тургенева и его критики» (Русский вестник. 1862. Т. 39. Май) и «О нашем нигилизме. По поводу романа Тургенева» (Русский вестник. 1862. Т. 40. Июль). Для того чтобы не «утонуть» в материале и сфокусировать угол зрения, можно воспользоваться словами М.Н. Каткова, объяснявшими отказ публициста от чисто эстетического анализа романа: «...мы не имели намерения разбирать роман и изображенные в нем характеры; мы только касаемся некоторых пунктов, имеющих общее значение, и по поводу их стараемся уловить и обозначить типические черты летучего явления нашей современной общественной среды» [18. С. 522]. Нас тоже будут интересовать, главным образом, не сам роман, не его художественные особенности и оценки их критиками, подробно рассмотренные в литературоведческих ра-

\footnotetext{
${ }^{1}$ В объявлении об издании журнала «Искра»: «На нашу долю выпадает разработка общих вопросов путем отрицания всего ложного во всех его проявлениях в жизни и искусстве. «... Средством достижения нашей цели... будет сатира в ее общем обширном смысле» (напечатано отдельной листовкой в 1858 г., цит. по: [15. С. 39]). Те же принципы были заявлены в объявлении о подписке на журнал «Гудок»: «Отрицание во имя честной идеи, сатира и юмор во всех их проявлениях, преследование грубого и узкого обскурантизма, произвола и неправды в нашей русской жизни - вот те начала, которыми будет руководствоваться редакция “Гудка"...»[16. С. 4 обл.] .

${ }^{2}$ Однако слово «нигилист» еще в 1829 г. использовал Н.И. Надеждин, назвав одну из своих статей «Сонмище нигилистов» (Вестник Европы. 1829. № 1-2).
} 
ботах ${ }^{1}$; наиболее интересной представляется именно реакция М.А. Антоновича, Д.И. Писарева, М.Н. Каткова на прозвучавшие в тексте термины «отрицание» и «отрицательное направление» ${ }^{2}$.

Все три автора часто используют термин «отрицательное направление» и говорят о явлении, обозначаемом так, как о чем-то хорошо известном и распространенном. Более того, по мнению Антоновича, «отрицательное направление» является главенствующим идеологическим течением, идеи которого «составляют принадлежность не молодого поколения только, а разделяются большинством и выражают общее современное направление и движение» [22. С. 77]. Что же обозначается этим выражением? В качестве синонимов можно подобрать несколько слов, встречающихся в названных статьях: «молодое поколение», «нигилизм» и «реалисты» - последнее только у Д.И. Писарева. Молодое поколение - понятно, а вот слово «нигилист» необходимо пояснить, от его определения зависит позиция того или иного автора в общественной борьбе. В статье М.А. Антоновича есть такая трактовка этого термина, скомпонованная из разных фрагментов романа «Отцы и дети»: «Нигилистом называется тот, который ничего не признает; который ничего не уважает; который ко всему относится с критической точки зрения; который не склоняется ни перед какими авторитетами; который не принимает ни одного принципа на веру, каким бы уважением ни был окружен этот принцип. < ..> Не признают искусства, не верят в науку и говорят даже, что наука вообще не существует. Теперь все отрицают, а строить не хотят; говорят, это не наше дело; сперва нужно место расчистить» [22. С. 77-78]. Сам М.А. Антонович не признает нигилизм в таком виде, как его представил И.С. Тургенев, - это, по словам критика, «карикатура, утрировка» - не более 3 . Д.И. Писарев, напротив, в общем принимает тургеневские формулировки, акцентируя связь «отрицательного направления» с естественными науками и медициной, и вводит еще один термин - «практическое направление». Получалось, что в отрицании была заложена своя положительная основа - отрицание «бесполезного». «Общий характер эпохи, - говорит Д.И. Писарев, - заключается в практическом направлении; мы все хотим жить и придерживаемся того правила, что соловья баснями не кормят» [23. С. 180]. Собственно, главные расхождения во взглядах радикальных критиков связаны с их отношением к образу Базарова, олицетворявшему собой «отрицательное направление» [22. С. 37].

М.А. Антонович недоволен Базаровым, потому что тот выведен слишком грубо («мелкий хвастунишка и пьянчужка» [22. С. 40]), да вдобавок еще проигрывает в карты, отрицает «все бессознательно, неразумно, вследствие ощущения, “нравится мне отрицать - и баста”» [22. С. 90]. Отрицать надо не

\footnotetext{
${ }^{1}$ См., напр.: [19], [20. С. 26-72].

2 «...Я придерживаюсь отрицательного направления - в силу ощущения. Мне приятно отрицать, мой мозг так устроен и баста!», - говорит Базаров Аркадию [21. С. 121].

${ }^{3}$ Такие суждения М. А. Антоновича дали возможность М.Н. Каткову представить дело в смешном, невыгодном для автора «Современника» виде: «Герой этот (Базаров/ - Д.К.) называет себя нигилистом; но г. Антонович ужасается при одном этом слове, ничего подобного не знает он в нашей литературе, и у него вянут уши, он краснеет от той дичи, которую городит этот нелепый нигилист. Г. Антонович божится, что в нашей литературе не было и помину о каком-нибудь отрицательном направлении» [18. С. 469]. Хотя М.А. Антонович, как мы видели, вовсе не отказывался признавать существование отрицательного направления.
} 
все, считает М.А. Антонович, а только такое искусство, как роман И.С. Тургенева, оказавшийся, в свою очередь, «беспощадной и... разрушительной критикой молодого поколения» [22. С. 45]. Да, «Базаров завирается - это, к сожалению, справедливо», - соглашается Д.И. Писарев. «Он сплеча отрицает вещи, которых не знает или не понимает...» [23. С. 179]. «Слишком неразборчивое отрицание» Базарова Д.И. Писарев объясняет тем, что юность героя прошла в труде (у Базарова просто не было времени изучать искусство и литературу), образованием и природной склонностью все поверять опытом. И себя, и Базарова Д.И. Писарев причисляет к «реалистам» («Мы смотрим холодно и трезво на все, что нас окружает...»), одобряя неидеальное изображение героя: «Отрицаемое нелепо, да и отрицатели тоже делают порою капитальные глупости; они все-таки стоят несоизмеримо выше отрицаемого, но тут еще честь больно невелика; стоять выше вопиющей нелепости не значит еще быть гениальным мыслителем» [23. С. 180].

После выступлений М.А. Антоновича и Д.И. Писарева выходят две статьи М.Н. Каткова в «Русском вестнике». Там тоже говорится, что нигилизм распространяется очень быстро и составляет «характеристическую черту умственной жизни в нашем отечестве за текущий момент» [18. С. 513]. М.Н. Катков отмечает крайне своевременное появление «Отцов и детей» и на примере романа подробно разбирает принципы «отрицательного направления», причины его успеха, характеризует образ Базарова. Истоки нигилизма М. Н. Катков видит не только в учениях европейских материалистов, но и в обстоятельствах русской истории, которая «сама вся основана на отрицанияХ» [18. С. 515], имея в виду, очевидно, петровский переворот и последовавшие за ним «механические» изменения. Катков использует такое выражение, как «религия нигилизма», у этой религии есть свои учители и фанатики. Популярность нигилизма заключается в его легкости и доступности («Bce peшено и все вздор» [18. С. 512]), а основной прием - «повальное отрицание»: «Чем решительнее отрицание, чем менее обнаруживает оно колебаний и сомнений, тем лучше, тем могущественнее авторитет, тем возвышеннее идол, тем непоколебимее вера» [18. С. 513].

В характеристике Базарова нас особенно интересует та связь, которую М.Н. Катков заметил между тургеневским героем и журналистами «Современника»: «...никто в этом журнале, - пишет М.Н. Катков, - не выражал так толково и умно, как тургеневский Базаров, всего того, что эти господа старались развивать на все лады...» [18. С. 470]. Схожее мнение высказал Н.Н. Страхов, логично указав и на второй журнал: «Система убеждений, круг мыслей, которых представителем является Базаров, более или менее ясно выражались в нашей литературе. Главными их выразителями были два журнала: “Современник” и "Русское слово", недавно заявившее их с особенною резкостью» [24. С. 184-185]. Итак, рупорами «отрицательного направления» считались некрасовский «Современник» и «Русское слово» в период редакторства Г.Е. Благосветлова, а также примыкавшие к ним сатирические издания («Искра», «Гудок») ${ }^{1}$. Противоположных взглядов, как мы видим, придержи-

\footnotetext{
1 «Для истории нашего нигилизма и определения его генеалогии, - писал И.С. Аксаков, - рекомендуем читателям обратиться к изучению русской журналистики с начала 60-х годов» [25. С. 5].
} 
вались славянофилы ${ }^{1}$, почвенники ${ }^{2}$. сотрудники М.Н. Каткова ${ }^{3}$. В то время как публицисты, в завуалированной форме отстаивавшие необходимость революции, делали упор на слове «отрицание», т.е. отрицание существующего миропорядка и представлявшихся им закоснелыми традиций и верований, авторы, выступавшие на страницах славянофильских и консервативных изданий, во главу угла ставили понятие «положительное», свидетельствующее о готовности увидеть в русской жизни хорошие стороны. Диалог двух направлений нередко отличался резкими нападками на оппонентов с двусмысленными высказываниями в их адрес и больше напоминал информационную войну (как это было в полемике «Эпохи» М.М. и Ф.М. Достоевских и «Современника» в лице М.А. Антоновича и М.Е. Салтыкова-Щедрина). Другое дело, что не менее рьяно, чем с «отрицателями», сторонники «положительного» полемизировали друг с другом. «Нет ничего труднее, - размышлял М.Н. Катков, - как найти в нашей общественной среде что-нибудь положительное, на чем могли бы сойтись между собою люди. Вы не свяжете трех человек на каком-нибудь положительном интересе; во всяком случае, связь между ними не продержится долго и не окажется плодотворною. Но зато нет ничего легче, как соединить между собою людей в чем-нибудь отрицательном. На положительном все перессорятся, и дело не пойдет; на отрицательном все легко сдружатся, и дело закипит» [18. С. 515]. Может быть, поэтому авторы, боровшиеся с нигилизмом и отрицанием, не предлагали четкой трактовки «положительного» - определить его всегда трудно. М.Н. Катков противодействие нигилизму надеялся найти в развитии «положительных интересов общественной жизни»: «религиозных, умственных, политических, экономических» [14. С. 527]. Однако подробно об этих «положительных интересах» редактор «Русского вестника» в своих статьях о тургеневском романе не говорит, также предпочитая «отрицательную» работу - развенчивать идеалы противников.

Исследование в русской журналистике XIX в. «положительного» и «отрицательного» направлений позволяет лучше понять расстановку общественных сил: публицисты, расходившиеся друг с другом в частностях, могут быть объединены в рамках того или иного направления. Главное, что термины «положительное» и «отрицательное» не придуманы позднейшими исследователями, а регулярно встречаются на страницах журналов и газетных полосах того времени. Сама проблема положительного или критического отображения жизни в журналистике и художественной литературе не теряет актуальности. Недаром до сих пор обсуждается необходимость позитивного взгляда

\footnotetext{
${ }^{1}$ Характерно, что Ф.В. Чижов в письме к И.С. Аксакову от 25 апреля 1877 г. говорил о необходимости издавать именно «положительную» газету: «Вам следует обдумать все дело и искренно сказать самому себе можете ли и желаете ли Вы вести газету положительную; что под Вашею редакциею она будет честною, об этом нечего и заикаться. Отрицание, критика... теперь значительные и отьявленные враги истинного успеха и истинного развития. Анализ, разбор, так; но разбор тем отличается от критики, что в нем спокойно видится благотворная сторона каждого явления и сторона вредная...» [26].

${ }^{2}$ В журнале братьев Достоевских «Время», вспоминал К.Н. Леонтьев, «положительное направление было еще шире, чем у славянофилов» [27. С. 101].

${ }^{3}$ CM.: [1].
} 
на явления окружающей действительности. В связи с этим важно обратиться к опыту предшественников, выслушать аргументы обеих сторон.

\section{Литература}

1. Трофимова T.A. «Положительное начало» в русской литературе XIX века: «Русский вестник» М.Н. Каткова: автореф. дис. ... канд. филол. наук. М., 2007. 21 с.

2. Киреевский И.В. Избранные статьи. М.: Современник, 1984. 384 с.

3. Смирнова 3.В. Философия раннего славянофильства и Шеллинг // Философия Шеллинга в России XIX века. СПб., 1998. С. 396-427.

4. Гегель Г.В. Ф. Наука логики: в 3 т. М., 1970. Т. 1. 504 с.

5. Гулыга А.В. Немецкая классическая философия. 2-е изд., испр. и доп. М.: Рольф, 2001. $416 \mathrm{c}$.

6. Шкуринов П.С. Позитивизм в России ХІХ века. М.: Изд-во Моск. ун-та, 1980. 416 с.

7. Словарь Академии Российской. СПб., 1793. Ч. 4.

8. Соколов П.И. Общий церковно-славяно-российский словарь. СПб., 1834. Ч. 2.

9. Словарь церковно-славянского и русского языка, составленный Вторым Отделением Императорской Академии наук: [в 4 т.] СПб., 1847. Т. 3.

10. Шевырев С.П. Об отечественной словесности. М.: Высш. шк., 2004. 304 с.

11. Аверкиев Д. В. Средний человек сороковых годов. Статья третья // Дневник писателя, ежемесячное издание Д.В. Аверкиева. СПб., 1885. Вып. 6. Июнь. С. 179-197.

12. Кунильский Д.А. «Положительная» журналистика против «отрицательной» литературы (статья Ю.Ф. Самарина «О мнениях “Современника”, исторических и литературных») // Журналистский ежегодник. 2012. № 1. С. 72-75.

13. Белинский В.Г. Собрание сочинений: в 9 т. М.: Худож. лит., 1982. Т. 8.784 с.

14. Кунильский Д.А. Достоевский и братья Аксаковы: спор о русской литературе. Петрозаводск: Изд-во ПетрГУ. 152 с.

15. Лемке М. Очерки по истории русской цензуры и журналистики XIX столетия. СПб.: Книгоиздательство М.В. Пирожкова, 1904. 427 с.

16. Об издании в 1862 году (год четвертый) политической и литературной еженедельной газеты «Русский мир» с сатирическим листком «Гудок» // Русский мир. 1861. № 102. С. 2-4 обл.

17. Страхов Н.Н. Воспоминания о Федоре Михайловиче Достоевском // Полн. собр. соч. Ф.М. Достоевского. Т. 1. СПб., 1883. С. 179-329 (первая пагинация).

18. Катков М Н. Собрание сочинений: в 6 т. СПб.: Росток, 2010. Т. 1.848 с.

19. Пустовойт П. Г. Роман И.С. Тургенева «Отцы и дети» и идейная борьба $60-$ х годов ХІХ века. М.: Изд-во МГУ, 1960. 328 с.

20. Троиикий В.Ю. Книга поколений: О романе И.С. Тургенева «Отцы и дети». М.: Книга, 1979. $112 \mathrm{c}$.

21. Тургенев И.С. Полное собрание сочинений и писем: в 30 т. М.: Наука, 1981. Т. 7.560 с.

22. Антонович М.А. Литературно-критические статьи. М.; Л.: ГИХЛ, 1961.516 с.

23. Писарев Д.И. Полное собрание сочинений и писем: в 12 т. М.: Наука, 2001. Т. 4. 395 с.

24. Страхов Н.Н. Литературная критика. М.: Современник, 1984. 432 с.

25. <Аксаков И.С.> Москва, 4 апреля // Русь. 1881. 4 апр. № 21. С. 2-5

26. Чижов Ф.В. Письмо к И.С. Аксакову от 25 апреля 1877 г. // ИРЛИ. Ф. 3. Оп. 4. Ед. хр. 675. Л. 88.

27. Леонтьев К.Н. Полное собрание сочинений и писем: в 12 т. / подгот. текста и коммент. В.А. Котельникова, О.Л. Фетисенко. СПб.: Владимир Даль, 2005. Т. 7, кн. 1. 560 с.

\section{THE DIALOGUE OF THE "POSITIVE" AND "NEGATIVE" DIRECTIONS IN RUSSIAN JOURNALISM IN THE 1860S}

Tomsk State University Journal of Philology, 2015, 6 (38), 159-168.

DOI: $10.17223 / 19986645 / 38 / 12$

Kunil'skiy Dmitry A., Petrozavodsk State University (Petrozavodsk, Russian Federation). E-mail: dkunilsky@mail.ru

Keywords: journalism, polemics, "positive" and "negative" directions, Fathers and Children, nihilism 
The author of the article tries to consider Russian journalism of the 19th century as a dialogue of the "positive" and "negative" directions. The terms "positive" and "negative" are analyzed in this article and the examples of their use in critical and publicistic works are given.

It is essential that at first the idea of "positive" and "negative" directions was developed in the sphere of literary criticism, which was especially focused on literature. Journalism or modern political and social situation were not the main objects for such works. So the problem of assertion and negation was one of the main for criticism in the 1840s. This issue was actively discussed in connection with works of the Natural School. On the one hand, Belinsky defended the "negative" direction of the Natural School which pictured only the dark sides of reality. On the other hand, such Belinsky's opponents as Slavophiles criticized the Natural School for exaggeration of faults and a supercilious attitude to common people. The social enthusiasm connected with the enthronement of Alexander II made these discussions more intensive. Special attention should be paid to the articles of Slavophiles' periodical Russkaya Beseda (1856-1860), because these works called writers to portray the light and positive moments of Russian life. We can see distinctly "positive" and "negative" parts in Russian journalism in the 1860s. It can be showed by the study of the polemics on I.S. Turgenev's novel Fathers and Children in such articles as M.A. Antonovich's "Asmodeus of Our Time" (Sovremennik. 1862. No. 3), D.I. Pisarev's "Bazarov" (Russkoe Slovo. 1862. No. 3) and two M.N. Katkov's works, which appeared later, "Turgenev's Novel and Its Critics" (Russkiy Vestnik. 1862. Vol. 39. May) and "About Our Nihilism. Apropos of Turgenev's Novel" (Russkiy Vestnik. 1862. Vol. 40. July). Special attention is paid to critics' reaction on the term "negative direction" which appeared in the text of the novel. Literary and aesthetic discussions transformed into real publicistic and political practice as intensive controversy on the present and the future of the country. The author of the article comes to a conclusion that the word "positive" means loyalty to the government and Church, adherence to national traditions. These ideas joined the periodicals of Slavophiles and Pochvenniks, M.N. Katkov's Moskovskie Vedomosti and Russkiy Vestnik. The Westerners, revolutionists and nihilists were called "negationists". They saw no ways for peaceful and consistent development in Russian life at that time. N.A. Nekrasov's Sovremennik and G.E. Blagosvetlov's Russkoe Slovo were the mouthpieces of the "negative" direction. The dialogue between the "positive" and "negative" directions was remarkable for harsh attacks on the opponents and resembled information warfare.

\section{References}

1. Trofimova, T.A. (2007) "Polozhitel'noe nachalo" v russkoy literature XIX veka: "Russkiy vestnik" M. N. Katkova [The "positive beginning" in Russian literature of the 19th century, Russkiy vestnik of M.N. Katkov]. Abstract of Philology Cand. Diss. Moscow.

2. Kireevskiy, I.V. (1984) Izbrannye stat'i [Selected articles]. Moscow: Sovremennik, 1984.

3. Smirnova, Z.V. (1998) Filosofiya rannego slavyanofil'stva i Shelling [The philosophy of early Slavophiles and Schelling]. In: Pustarnakov, V.F. (ed.) Filosofiya Shellinga v Rossii XIX veka [Philosophy of Schelling in Russia of the 19th century]. St. Petersburg: RKhGI.

4. Hegel, G.W.F. (1970) Nauka logiki: $v 3 t$. [Science of Logic: in 3 v.]. Translated from German. V. 1. Moscow: Mysl'.

5. Gulyga, A.V. (2001) Nemetskaya klassicheskaya filosofiya [German classical philosophy]. 2nd ed. Moscow: Rol'f.

6. Shkurinov, P.S. (1980) Pozitivizm v Rossii XIX veka [Positivism in the 19th-century Russia]. Moscow: Moscow State University.

7. Imperial Academy of Sciences. (1793) Slovar' Akademii Rossiyskoy [Dictionary of the Russian Academy]. V. IV. St. Petersburg: pri Imperatorskoy Akademii Nauk.

8. Sokolov, P.I. (1834) Obshchiy tserkovno-slavyano-rossiyskiy slovar' [General ChurchSlavonic-Russian dictionary]. V. II. St. Petersburg: v Tipografii Imperatorskoy Rossiyskoy Akademii.

9. Second branch of the Imperial Academy of Sciences. (1847) Slovar' tserkovno-slavyanskogo $i$ russkogo yazyka, sostavlennyy Vtorym Otdeleniem Imperatorskoy Akademii nauk. $V 4 t$. [Dictionary of Church Slavonic and Russian, made up by the Second Branch of the Imperial Academy of Sciences. In 4 v.] V. III. St. Petersburg: v Tipografii Imperatorskoy Akademii Nauk.

10. Shevyrev, S.P. (2004) Ob otechestvennoy slovesnosti [On Russian literature]. Moscow: Vysshaya shkola.

11. Averkiev, D.V. (1885) Sredniy chelovek sorokovykh godov. Stat'ya tret'ya [An average person of the forties. Article Three]. Dnevnik pisatelya. VI: June. pp. 179-197. 
12. Kunil'skiy, D.A. (2012) "Polozhitel'naya" zhurnalistika protiv "otritsatel'noy" literatury (stat'ya Yu. F. Samarina "O mneniyakh "Sovremennika", istoricheskikh i literaturnykh") ["Positive" journalism against "negative" literature (Yuri Samarin's "On the Views of Sovremennik, historical and literary)]. Zhurnalistskiy ezhegodnik - Journalistic Yearbook. 1. pp. 72-75.

13. Belinsky, V.G. (1982) Sobr. soch.: v9 t. [Works: in 9 v.]. V. 8. Moscow: Khudozhestvennaya literatura.

14. Kunil'skiy, D.A. (n.d.) Dostoevskiy i brat'ya Aksakovy: spor o russkoy literature [Dostoevsky and Aksakov brothers: a dispute about Russian literature]. Petrozavodsk: Petrozavodsk State University.

15. Lemke, M. (1904) Ocherki po istorii russkoy tsenzury i zhurnalistiki XIX stoletiya [Essays on the history of Russian journalism and censorship of the 19th century]. St. Petersburg: Knigoizdatel'stvo M. V. Pirozhkova.

16. Anon. (1861) Ob izdanii v 1862 godu (god chetvertyy) politicheskoy i literaturnoy ezhenedel'noy gazety "Russkiy mir" s satiricheskim listkom "Gudok" [On the publication in 1862 (the fourth year) of the political and literary weekly newspaper Russkiy mir with a satirical piece of Gudok]. Russkiy mir. 102. pp. 2-4.

17. Strakhov, N.N. (1883) Vospominaniya o Fedore Mikhayloviche Dostoevskom [Memories of Fyodor Dostoevsky]. In: Polnoe sobranie sochineniy F.M. Dostoevskogo [Complete Works of F.M. Dostoevsky]. V. 1. St. Petersburg: Tipografiya A. S. Suvorina.

18. Katkov, M.N. (2010) Sobr. soch.: v 6 t. [Works: in 6 v.]. V. 1. St. Petersburg: Rostok.

19. Pustovoyt, P.G. (1960) Roman I.S. Turgeneva "Ottsy i deti" $i$ ideynaya bor'ba 60-kh godov $X I X$ veka [Turgenev's novel Fathers and Sons, and ideological struggle of the 1860s]. Moscow: Moscow State University.

20. Troitskiy, V.Yu. (1979) Kniga pokoleniy. O romane I. S. Turgeneva “Ottsy i deti” [A book of generations. About Turgenev's novel Fathers and Sons]. Moscow: Kniga.

21. Turgenev, I.S. (1981) Poln. sobr. soch. i pisem: v 30 t. [Complete works: in 30 v.]. V. 7. Moscow: Nauka.

22. Antonovich, M.A. (1961) Literaturno-kriticheskie stat'i [Literary-critical articles]. Moscow; Leningrad: Gosudarstvennoe izdatel'stvo khudozhestvennoy literatury.

23. Pisarev, D.I. (2001) Poln. sobr. soch. i pisem: v 12 t. [Complete works and letters: in 12 v.]. V. 4. Moscow: Nauka.

24. Strakhov, N.N. (1984) Literaturnaya kritika [Literary criticism]. Moscow: Sovremennik.

25. 〈Aksakov, I.S.> (1881) Moskva, 4 aprelya [Moscow, April 4]. Rus'. 4 April:21. pp. 2-5.

26. Chizhov, F.V. (1877) Pis'mo kI. S. Aksakovu ot 25 aprelya 1877 g. [Letter to I.S. Aksakov on April 25, 1877]. The Pushkin House. Fund 3. List 4. Unit 675. P. 88.

27. Leont'ev, K.N. (2005) Poln. sobr. soch. i pisem: v 12 t. [Complete works and letters: in $12 \mathrm{v}$.]. V. 7. Book 1. St. Petersburg: Vladimir Dal'. 